\title{
Designing and psychoanalysis: A comprehensive questionnaire on coping with domestic violence against women in Iranian society
}

\author{
Zeinab Mohhamadian ${ }^{1}$, Jamileh Mohtashami ${ }^{2}$, Camelia Rohani ${ }^{3}$, Tayebeh Jamshidi ${ }^{4}$
}

${ }^{1}$ M.Sc. Student, Research Committee, School of Nursing \& Midwifery, Shahid Beheshti University of Medical Sciences, Tehran, Iran

${ }_{2}^{2}$ Ph.D., Assistant Professor, Psychiatric Nursing Department, School of Nursing \& Midwifery, Shahid Beheshti University of Medical Sciences, Tehran, Iran

${ }^{3}$ Ph.D., Assistant Professor, Community Health Nursing Department, School of Nursing \& Midwifery, Shahid Beheshti University of Medical Sciences, Tehran-Iran

${ }^{4}$ M.Sc. of Nursing, Department of Psychiatric Nursing, School of Nursing and Midwifery, Shahid Beheshti University of Medical Sciences, Tehran, Iran

\section{Type of article: Original}

\begin{abstract}
Background: Domestic violence is the third sociopathology after addiction and child abuse in Iran. Fifty-six percent of Iranian women in the range of 17-32 years old are exposed to the highest domestic violence. Objective: The aim of this study was to design and psychoanalyze a comprehensive questionnaire on coping with domestic violence against women in Iranian society.

Methods: This study was carried out on a random sample of women exposed to domestic violence and referred to the health and care center of Shahid Beheshti University of Medical Sciences in Tehran, and Forensic Medical Centers in Urmia city (Iran), in 2017. Two hundred questionnaires were distributed among the participants. One hundred sixty-eight questionnaires were returned to the researchers for data analysis. Eight of those were excluded from the analysis because of incompleteness. Finally, exploratory factor analysis was performed.

Results: After reviewing the literature, a questionnaire with 32 items was developed. Content validity ratio (0.95) and content validity index (0.97) were obtained. The results of exploratory factor analysis indicated that the questionnaire explained $69.34 \%$ of the data variance. Cronbach's alpha coefficient, and test-retest methods were used for determining the reliability and the obtained value, which were 0.82 and 0.81 , respectively.

Conclusion: Validity and reliability of the questionnaire with 32 items were confirmed. The tool can be utilized to measure how women cope with domestic violence.

Keywords: Domestic violence, Women, Psychoanalysis, Structure validity, Content validity
\end{abstract}

\section{Introduction}

Violence is an intentional behavior to harm oneself or others, and according to some scholars, it might be a natural or acquired behavior (1). Violence against women is an abnormal behavior between two opposite genders, where the female, due to her gender, is oppressed by the male (2). The term "violence against women" refers to any violent action against female gender, which might be featured by sustaining trauma and physical/psychological/sexual pain, which might result in serious injuries (3). Violence against women includes physical, psychological, and sexual injuries sustained in the family and society (4). Domestic violence includes wife abuse, female abuse, and partner abuse and it is considered as a global problem (5). The problem is beyond cultural/racial boundaries or social/economic/educational/age classes (1). Violence against women is a problem obstructing the path to reaching

\section{Corresponding author:}

Assistant Professor Dr. Jamileh Mohtashami, Psychiatric Nursing Department, School of Nursing \& Midwifery, Shahid Beheshti University of Medical Sciences, Tehran, Iran.

Tel: +98.2166568158, Email: j_mohtashami@sbmu.ac.ir

Received: February 04, 2017, Accepted: September 12, 2017, Published: January 2018

iThenticate screening: September 18, 2017, English editing: January 13, 2018, Quality control: January 15, 2018

This article has been reviewed / commented by three experts

(C) 2018 The Authors. This is an open access article under the terms of the Creative Commons Attribution-NonCommercialNoDerivs License, which permits use and distribution in any medium, provided the original work is properly cited, the use is non-commercial and no modifications or adaptations are made. 
equality, development, and peace. The old aged failure in upholding and improving practical limitations against violence against women is an unsolved problem worldwide. Persistence and stagnancy of domestic violence highlight a social violence crisis, which may threaten the psychological health of society (3). Social attitudes toward violence, women, marriage, and family, inability of the official bodies to improve and change the male oriented structure of organizations, lack of economic/social support, and lack of knowledge among women about available facilities are some of the causes of violence against women (6). The time periods of a woman's life in which she suffers from violence are: the first year of marriage, periods of financial hardship, child birth in the family, middle age, and pregnancy; these stages are featured with violence against women at least once a month (7). Violence against women is the most common crime with the least punishment around the world (8). About $5 \%$ of medical problems among women at the age range of 15-42 years in the developed and developing countries are due to violence against women (9). Results of studies have indicated that two million women suffer from domestic violence every year in the United States and as a result, 73,000 cases are hospitalized and 1,500 die (10). Also, every week, on average, two women are killed by their partner in the United Kingdom (11); however, there is no reliable report about the statistics of domestic violence in Iran. Experts at the Iranian Women's Affairs Center believe that not all the cases of domestic violence in Iran are reported (12). Emergence and increase of the outcomes of domestic violence (e.g. depression, attempted suicide) have placed this problem at the top of the social problems and issues in Iran. Many social planners and policy makers have expressed their concerns in this regard knowing that women's role as a social actor is not negligible (13). Taking into account the status quo of the social and cultural factors in Iran (patriarchic attitudes and lack of belief in using liberal approaches in families), domestic violence against women by their partner is a serious social issue in Iranian society. Violence against women is a tool to deepen men's authority in private and public arenas (14). In the studies performed in Iran in this field, only the concept of domestic violence against women has been studied, the design of a questionnaire coping with domestic violence against women has not been considered and there are no questionnaires in Persian on coping with domestic violence. In light of this introduction, importance of domestic violence and its outcome, and necessity to deal with the social problem, the present study is an attempt to develop and determine psychometric properties of a questionnaire on the ways to cope with domestic violence. This can be the first step in planning to fight this phenomenon. Women's views and opinions about coping with domestic violence can lead to an appropriate reaction in critical situations and the reduction of serious danger. According to the study of Liboko et al. (15) on women suffering from domestic violence, $60 \%$ of them believed that they should endure the violence because of their children, family responsibility, financial problems, alcohol consumption by the husband, religious and cultural norms. Also, $70 \%$ of those women stated that to escape from the violence, they took refuge with their relatives. Sixty percent of samples stated that they referred to a health and care center. Sabina and Tindal (16) investigated 3 types of matching strategy in women suffering from the domestic violence. Their findings showed that matching resources such as general health, employment, and social support affect the use of strategies. Ninety percent of samples used at least one of the problem-oriented matching strategies. Nineteen percent of them received no help or support. The study showed that there is a significant correlation between education level and attitude toward domestic violence and also between marital status and mental norms about coping with domestic violence. Moreover, there is a negative correlation between self-efficacy and attitude toward domestic violence and between attitude toward domestic violence and violence. Findings showed that there was no significant correlation between attitude toward domestic violence and sexual violence. In result, factors relating to domestic violence against women include demographical specifications (e.g. age, job, education, and marital status), self-efficacy, mental norms, attitudes toward domestic violence, and types of violence. It has been suggested that the mentioned factors should be used to empower women, so that they can cope with domestic violence. In the literature (17), the women's reaction to the violence was categorized into three states: The first category consisted of women who believed the violence would be short-lived and temporary. The women believed that their situation would improve. The second category consisted of women who remained in the same situation and there was no intervention because of their fear and disability to cope with the situation. They were not interested in changing the situation. Saberian et al. (14) surveyed the factors effective on emergence of domestic violence and coping methods from viewpoints of women referred to the care and health center of Semnan. They reported that traditional defensive approaches like ending long-term relationships and leaving home were not effective coping methods. On the other hand, they argued that remaining silent, discussing the problem after calming the partner, asking for help from an older member of the family, and seeking experts' consultation were more effective approaches (14). Generally, the problem is common in Iran, and having a correct and logical approach to coping with domestic violence, that predominantly includes women, is essential. Also, there is lack of evidence in order to study the methods in which to cope with violence, and there is a lack of a validated questionnaires in this field. Therefore, this study aimed at designing a questionnaire about the methods in which to cope with violence 
against women in order to be used in forensic medicine and by researchers and women who are victims of this type of violence.

\section{Material and Methods}

\subsection{Research design and participants}

This methodological study was carried out on experts and the women referred to clinics affiliated with Shahid Beheshti University of Medical Sciences (in Tehran), and Forensic Medical Centers in Urmia city in Iran in 2017. The number of people referred to the clinics of the Tehran is high. Also, the cultural variety in Tehran is more than that of other cities, therefore we are able to generalize obtained results to the whole country. The reason for choosing Urmia's Forensic Medicine is so that it can be accessible. After securing the required permissions from the university, sampling was performed through purposeful sampling. Inclusion criteria were women facing domestic violence for at least one year and willingness to share the experiences.

\subsection{Instrument validity procedure and factor analysis}

At first, the statements that constituted the main structure of the questionnaire were designed based on literature review, interview, and consulting with the experts. The primary scale to measure coping styles against domestic violence in women included 37 statements. Psychometric properties were examined afterward. The total number of the samples required for face and construct validity of the instrument was 160 individuals ( 80 chosen from Urmiabased Forensic Medicine and 80 chosen from Tehran-based clinics). To have more objective approaching statements and to make them more representative of a specific behavior that pictures how women cope with domestic violence, at face validity stage the participants were asked about the level of understandability, inconsistency, and ambiguity of the statements. To determine content validity through qualitative and quantitative methods, eight experts of designing similar tools, and the experts of domestic violence were consulted. With regard to qualitative survey, the experts were asked to study the tool and provide feedback. With respect to quantitative validity, content validity ratio (CVR) was used; so that the experts were asked to score each statement from 0 to 2 ( $2=$ it is essential; $1=$ useful but not essential; $0=$ not essential). Numerical value of CVR was determined based on Lawshe' s table of “critical value" ; and then, Waltz and Bausell content validity ratio (CVI) was used to examine content validity (a statement would be acceptable when CVI $\geq 75 \%$ ). Moreover, the statements that were rated as improper by the experts were removed. Afterward, internal consistency of the statements was examined. Exploratory factor analysis was used to determine construct validity of the questionnaire. Two hundred questionnaires were distributed among the samples. One hundred sixty-eight questionnaires were collected in the final stage; eight of which were excluded from the analysis because of incompleteness. The exploratory factor analysis was performed through 160 remaining questionnaires. To analyze the data based on factor analysis, Kaiser-Meyer-Olkin's (KMO) measure of sampling adequacy was used. Value of the measure varies between 0 and 1 and the closer it is to "1" the better the factor analysis (18). To ascertain if the correlation matrix is significantly different from 0 and if the factor analysis is acceptable, the Bartlett test was used. Afterward, the rotated matrix of the designed questionnaire was examined. Factor load refers to correlation between one variable and one factor, which is used to determine if the variable of a factor after varimax or factor rotation should be deleted or kept. There are different approaches to determine the number of factors in explorative factor analysis, and two of them are variance of a statement and mean correlation (0.3-0.7 or higher) (19).

\subsection{Reliability of the instrument}

Reliability of the questionnaire was determined through internal consistency, test-retest, and intra-class correlation (ICC). To this end, the questionnaire was provided to one group of the participants $(n=30)$ at two different occasions and then the Chronbach's alpha correlation coefficient (internal consistency) was obtained. In addition, to determine reliability and consistency, feedback from eight experts was used based on ICC.

\subsection{Research ethics}

In line with ethical considerations, the license and letter of introduction was obtained from Shahid Beheshti University of Medical Sciences (IR.SBMU.phnm.1394.252). The researchers considered the provisions of the Helsinki Declaration such as explaining the research objectives to the participants, obtaining written informed consent from participants, and voluntary participation in the study, right to exit from the study without any question, harmless intervention, complete explaining the research process to the participants, and answering the questions of participants and presenting the results of the study if asked. 


\section{Results}

The "Coping with Domestic Violence against Women" questionnaire with 37 statements, was designed to examine ways adopted by women, to cope with domestic violence. Face validity (qualitative) of the questionnaire was examined by eight experts and few adjustments were made to make the questionnaire more understandable. Statements No. 32-37 were modified at content validity assessment stage (Table 1).

Table 1. Total data variance

\begin{tabular}{|c|c|c|c|c|c|c|}
\hline \multirow{2}{*}{$\begin{array}{l}\text { Statement } \\
\text { no. }\end{array}$} & \multicolumn{3}{|c|}{ Specific value } & \multicolumn{3}{|c|}{ Explained variance percent } \\
\hline & Total & $\begin{array}{l}\text { Percentage of } \\
\text { variance }\end{array}$ & $\begin{array}{l}\text { Accumulated } \\
\text { percentage }\end{array}$ & Total & $\begin{array}{l}\text { Percentage of } \\
\text { variance }\end{array}$ & $\begin{array}{l}\text { Accumulated } \\
\text { percentage }\end{array}$ \\
\hline 1 & 6.688 & 20.900 & 20.900 & 6.688 & 20.900 & 20.900 \\
\hline 2 & 3.046 & 9.518 & 30.419 & 3.046 & 9.518 & 30.419 \\
\hline 3 & 2.557 & 7.991 & 38.410 & 2.557 & 7.991 & 38.410 \\
\hline 4 & 2.042 & 6.382 & 44.792 & 2.042 & 6.382 & 44.792 \\
\hline 5 & 1.70 .9 & 5.340 & 50.132 & 1.709 & 5.340 & 50.132 \\
\hline 6 & 1.602 & 5.007 & 55.139 & 1.602 & 5.007 & 55.139 \\
\hline 7 & 1.380 & 4.313 & 59.452 & 1.380 & 4.313 & 59.452 \\
\hline 8 & 1.100 & 3.436 & 62.888 & 1.100 & 3.436 & 62.888 \\
\hline 9 & 1.062 & 3.319 & 66.207 & 1.062 & 3.319 & 66.207 \\
\hline 10 & 1.003 & 3.134 & 69.341 & 1.003 & 3.134 & 69.341 \\
\hline 11 & 0.954 & 2.981 & 72.322 & & & \\
\hline 12 & 0.727 & 0.586 & 74.908 & & & \\
\hline 13 & 0.818 & 2.555 & 77.463 & & & \\
\hline 14 & 0.767 & 2.398 & 79.861 & & & \\
\hline 15 & 0.727 & 2.272 & 82.133 & & & \\
\hline 16 & 0.659 & 2.060 & 84.193 & & & \\
\hline 17 & 0.572 & 1.787 & 85.980 & & & \\
\hline 18 & 0.530 & 1.657 & 87.637 & & & \\
\hline 19 & 0.472 & 1.475 & 89.112 & & & \\
\hline 20 & 0.460 & 1.438 & 90.550 & & & \\
\hline 21 & 0.416 & 1.302 & 91.851 & & & \\
\hline 22 & 0.406 & 1.269 & 93.120 & & & \\
\hline 23 & 0.361 & 1.128 & 94.249 & & & \\
\hline 24 & 0.343 & 1.103 & 95.352 & & & \\
\hline 25 & 0.296 & 0.925 & 96.277 & & & \\
\hline 26 & 0.269 & 0.841 & 97.118 & & & \\
\hline 27 & 0.243 & 0.761 & 97.879 & & & \\
\hline 28 & 0.194 & 0.607 & 98.485 & & & \\
\hline 29 & 0.155 & 0.484 & 98.970 & & & \\
\hline 30 & 0.132 & 0.413 & 99.383 & & & \\
\hline 31 & 0.111 & 0.347 & 99.730 & & & \\
\hline 32 & 0.087 & 0.270 & 100.000 & & & \\
\hline
\end{tabular}

Five questions were removed because the experts found them similar to other questions in the questionnaire. Each statement was scored using Likert's five-point scale $(0=$ never; $1=$ barely; $2=$ sometimes; $3=$ most of the time; $4=$ always). The final score was obtained as total scores of all the statements. The scores were categorized as excellent (97-128), good (65-96), moderate (33-64); and weak (0-32). The findings pertinent to numerical value of CVR showed that statements with CVR $>0.49$ were significant and, therefore, must remain in the questionnaire. It is notable that, total CVR and CVI of the questionnaire were obtained as 0.95 and 0.97 respectively; so that total understandability, simplicity, and relevance scores were obtained as $0.96,0.98$, and 0.97 respectively. At construct validity stage based on explorative factor analysis, the tool was administered to 160 participants. At factor analysis stage, Bartlett test and KMO measure were used to examine adequacy of correlation pattern among the variables. Sampling adequacy was examined using KMO test (0.727). Bartlett test on the correlation matrix was obtained as 225.93 , which was significant at confidence level of $99 \%$ and indicated acceptable factor load of the data 
$(\mathrm{p}<0.0001)$. Factor load examination indicated the portion of variance explained by each statement, based on which the main elements of the primary commonalities were computed using all the available elements (in all the cases ' 1 ' was obtained). Total explained variance by the factors showed that 10 factors had specific value above 1 and totally explained $69.34 \%$ of the variance. Latent factors of the tool were extracted using data flow diagram and based on the factor load, 10 factors had specific values above 1, which supported our results for total explained variance (Table 1, 2). Reliability of the tool was determined based on internal consistency so that with Cronbach's alpha of all the statements equal with 0.82 , none of the statements were removed at this stage. Reliability and consistency of the questionnaire was checked using test-retest method. The obtained r-values at two stages were equal with 0.81 . Given the correlation value $(r>0.70)$, the obtained value of reliability based on test-retest was acceptable. ICC value based on the feedback from eight experts was 0.79 with degree of freedom of 31 and 217; which was acceptable, and showed higher correlation between the assessments made by the experts.

Table 2. Rotated matrix of the questionnaire "Coping with Domestic Violence against Women"

\begin{tabular}{|c|c|c|c|c|c|c|c|c|c|c|}
\hline \multicolumn{11}{|c|}{ Components } \\
\hline & 1 & 2 & 3 & 4 & 5 & 6 & 7 & 8 & 9 & 10 \\
\hline p14 & 0.855 & & & & & & & & & \\
\hline p13 & 0.848 & & & & & & & & & \\
\hline p7 & 0.782 & & & & & & & & & \\
\hline $\mathrm{p} 8$ & 0.737 & & & & & & & & & \\
\hline p9 & 0.585 & & & & & & & & & \\
\hline p30 & & 0.771 & & & & & & & & \\
\hline p18 & & 0.735 & & & & & & & & \\
\hline p19 & & 0.723 & & & & & & & & \\
\hline p21 & & 0.568 & & & & & & & & \\
\hline p15 & & & 0.848 & & & & & & & \\
\hline p16 & & & 0.795 & & & & & & & \\
\hline p17 & & & 0.556 & & & & & & & \\
\hline p3 & & & & 0.824 & & & & & & \\
\hline $\mathrm{p} 4$ & & & & 0.731 & & & & & & \\
\hline p2 & & & & 0.664 & & & & & & \\
\hline p1 & & & & 0.498 & & & & & & \\
\hline p26 & & & & & 0.686 & & & & & \\
\hline p23 & & & & & 0.649 & & & & & \\
\hline p27 & & & & & 0.502 & & & & & \\
\hline p29 & & & & & 0.494 & & & & & \\
\hline p22 & & & & & 0.486 & & & & & \\
\hline p25 & & & & & 0.452 & & & & & \\
\hline p32 & & & & & & 0.823 & & & & \\
\hline p31 & & & & & & 0.809 & & & & \\
\hline p24 & & & & & & & 0.728 & & & \\
\hline p28 & & & & & & & 0.683 & & & \\
\hline p10 & & & & & & & & 0.817 & & \\
\hline p11 & & & & & & & & 0.615 & & \\
\hline p6 & & & & & & & & & 0.849 & \\
\hline p5 & & & & & & & & & 0.705 & \\
\hline p12 & & & & & & & & & & 0.717 \\
\hline p20 & & & & & & & & & & 0.578 \\
\hline
\end{tabular}

\section{Discussion}

Although, data gathering is a critical stage of a research work and having reliable data needs standard tools (20), our survey showed that there was no standard questionnaire about the methods of coping with domestic violence used by women in Iran, not to mention the importance of the issue of domestic violence. There are many challenges in the way of designing a tool to measure domestic violence, including how to design the tool (21). On the other hand, having better knowledge about women's attitudes and beliefs about domestic violence might be useful in helping 
them to show better reaction in such critical situations and reduce the risks (15). Examining methods of coping with domestic violence adopted by women needs a standard tool for measurement. Based on the primary reviews, a questionnaire with 37 statements was designed and of which face validity (qualitative) was supported by the experts. In addition, CVR and CVI of the questionnaire were obtained equal with 0.91 and 0.97 respectively; while total understandability, simplicity, and relevance were obtained equal with 0.96, 0.98, and 0.97 respectively. Bahreini et al. (22), Ghodrati et al. (23), Jabari et al. (24), and Mohtashami et al. (25), used experts' feedback to determine face and content validity of their tools. In addition, results of explorative factor analysis showed that KMO value was 0.72 ; this figure indicated the extent of the variance explained by the factors and it is more acceptable when it is closer to 1 . The KMO value of 0.72 hinted acceptable adequacy of the sampling for doing factor analysis. Bartlett test with level of confidence of $99 \%$ supported factorial capacity of the data and specific value of data flow diagram of the 10 factors was more than 1; so, they totally explained $69.34 \%$ of the variance. Lieu and Cheng (26) used exploratory factor analysis to determine construct validity. Polit and Beck (27) used factor analysis for construct validity as a method to determine the clusters pertinent to the statements of a tool. Cronbach's alpha was used to check reliability of the tool and it was obtained as 0.82 . Correlation coefficient of the designed questionnaire was 0.81, which indicated good reliability based on test-retest method. Bahreini et al. (22), Jabari et al. (24), Mohtashami et al. (25), and Leiu (26) used Cronbach's alpha to examine internal consistency. Moreover, total ICC of the tool was obtained as 0.79; which indicated acceptable correlation among the experts. Mohtashami et al. (3) used ICC method to examine reliability based on correlation among observers.

\section{Conclusions}

As the results about face, content, and construct validity and reliability (based on internal consistency and correlation) of the tool showed, validity and reliability of the tool were supported. The purpose of designing the tool was to examine methods of coping with domestic violence by women. Taking into account the lack of similar tools, the designed tool can be used as a comprehensive tool to examine methods of coping with domestic violence adopted by women. The tool can be also used by family consultants and psychologists as well.

\section{Acknowledgments:}

The study was carried out based on research project No. 6937, approved by the Research Ethics Committee (No.: IR.SBMU.phnm.1394.252, dated: 19 Jan. 2016) at the Faculty of Nursing and Midwifery, Shahid Beheshty University of Medical Sciences and Health Services (Tehran, Iran). The authors express their gratitude toward the professors of the university, authorities of Urmia Forensic Center, and staff and colleagues in the Tehran-based clinics affiliated with Shahid Beheshti University of Medical Science.

\section{Conflict of Interest:}

There is no conflict of interest to be declared.

Authors' contributions:

All authors contributed to this project and article equally. All authors read and approved the final manuscript.

\section{References:}

1) Saroukhani B. An introduction to family sociology. Tehran: Soroush Publication; 2010.

2) Qalibaf A. Surveying women's experience about domestic violence. MSc dissertation. University of Tehran; 2009.

3) Mohtashami J, Yaghmaei F, Jafari A, Alavi Majd H, Ahmadi A. Related factors to coping with domestic violence in women who refer to Forensic Medicine Centers in Tehran. JHPM. 2014; 3(2): 54-64.

4) Walker LE. Psychologist and domestic violence around the world. Journal of American Psychologist. 2009: 54: 21-8. doi: 10.1037/0003-066X.54.1.21.

5) Vameghi M, Mohammadreza KA, Sajadi H. Domestic Violence in Iran: Review of 2001-2008 literature. Social Welfare. 2014; 13(50): 37-70.

6) Hayati EN, Högberg U, Hakimi M, Ellsberg MC, Emmelin M. Behind the silence of harmony: risk factors for physical and sexual violence among women in rural Indonesia. BMC Woman's Health; 2011; 23(11): 52.

7) Soleimani M. History of violence against women. Tehran: Abrokh; 2011.

8) Loke WC, Torres C, Bacchus L, Fox E. Domestic violence in a genitourinary medicine setting. An anonymous prevalence study in women. Int J STD AIDS. 2008; 19(11): 519-747. doi: 10.1258/ijsa.2008.008117. PMID: 18931267. 
9) World Health Organization. Addressing violence against women and achieving the Millennium Development Goals, Department of Gender, Women and Health Family and Community Health. 2009.

10) Libuku E, Wilkinson W. Exposure to domestic violence during pregnancy: Perceptions and coping mechanisms of vulnerable group. Health South Australia. 2008; 13(2): 3-11. doi: 10.4102/hsag.v13i2.275.

11) Smaieli R. A sociological survey of domestic violence against women and the effective social factors on it MSc. Dissertation, Islamic Azad University, Garmsar Branch. 2014.

12) Ismaili R. Cognitive comprehension of violence against women and its social factors affecting it. Master's degree dissertation, Islamic Azad University, Garmsar Branch. 2014.

13) Abbasi M. A comparative survey of personality disorders in mothers with of normal and behavioral disorder pre-school children. MSc dissertation, Allame Tabatabaie University. 2012.

14) Saberian M, Atashnafas A, Behnam B. Surveying the factors effective on domestic violence and coping methods adopted by the women referred to Semnan-based clinics. Semnan University of Medical Science Press. 2011.

15) Didace A. Liboko, The emergence of the African regional collective security system or the pax africana, Legal and Political Review of the French-speaking States: 2009; 63(2).

16) Sabina C, Tindale RS. Abuse characteristics and coping resources as predictors of problem-focused coping strategies among battered women. Violence Against Women. 2008; 14(4). doi: 10.1177/1077801208314831. PMID: 18359879.

17) Lofong, Loke WC, Torres C, Bacchus L, Fox E. Domestic violence in a genitourinary medicine setting. An anonymous prevalence study in women. Int J STD AIDS. 2008; 19(11): 747-51.

18) Kazazi A, Sohrabi R. Introducing elements and indices of supply chain agility of Iran national oil company. Change Management Journal. 2010; 2(4).

19) Hatami Pour Kh. Designing and psychometric properties of a scale to examine spiritual needs of cancer patients PhD dissertation in nursing. Shahid Beheshti University of Medical Science. 2014.

20) Yaghmaei F. Behavioral Measurement in Research with Valid and Reliable Instruments. Shahid Beheshti University of Medical Sciences Publication; 2008.

21) Fieldhouse E, Tranmer M. something about young people or something about elections? Electoral participation of young people in Europe: Evidence from a multilevel analysis of the European Social Survey. European journal of political research. 2007; 46(6): 822-797.

22) Bahreini F, Owlia P, Eftekhari MB, Forouzan AS, Farahani M, Ghanei M. Health research priority setting in Iran: Introduction to a bottom up approach. J Res Med Sci. 2011; 16(5): 691-8. PMID: 22091294, PMCID: PMC3214383.

23) Ghodrati F. A seven-year study about the epidemiology of smoking, alcohol, drugs and psychotropic consumption along with legal abortion in cases referred to forensic medicine centers in Fars. International journal of medical research and review. 2016; 4(3).

24) Jabari S, Medicus W. Domestic violence incident leads to discovery of drugs, weapons. 2013. Available from: http://beaufortpublicsafety.com.

25) Mohtashami J, Yaghmaei F, Jafari A, Alavi Majd H, Ahmadi A. Related factors to coping with domestic violence in women who refer to Forensic Medicine Centers in Tehran. Journal of Health Promotion Management. 2014; 3(2): 54-64.

26) Li Y, Chen X. Exploratory factor analysis of the functional movement screen in elite athletes. J Sports Sci. 2015; 33. doi: 10.1080/02640414.2014.986505.

27) Polit DF, Beck CT. Essentials of Nursing Research: Appraising Evidence for Nursing Practice. 7th Ed. Philadelphia: Wolters Kluwer Health/Lippincott Williams \& Wilkins; 2010. 